\title{
Construction and reliability of the Japanese version of the Adolescent Egocentrism-Sociocentrism (AES) scale and its preliminary application in the Japanese university students
}

\author{
Mayumi Yamamoto', Masahito Tomotake ${ }^{2}$, and Tetsuro Ohmori² \\ ${ }^{1}$ The University of Tokushima Faculty of Integrated Arts and Sciences, Tokushima, Japan, and \\ ${ }^{2}$ Department of Psychiatry, Institute of Health Biosciences, the University of Tokushima Graduate \\ School, Tokushima, Japan
}

\begin{abstract}
In recent years, the problem of interpersonal relationships has been reported to be associated with various adolescent psychiatric problems. Egocentrism is one factor related to the problem of interpersonal relationships. The Adolescent EgocentrismSociocentrism (AES) scale is used to assess egocentrism in Western countries, but no such scale has been developed in Japan.

The purpose of our current study was to develop the Japanese version of the AES scale and investigate the relationship between the egocentrism assessed by the AES scale and the self-consciousness assessed by the Japanese version of the self-consciousness scale. The original version of the AES scale was first translated into Japanese using the forward backward method and examined for factorial reliability and validity. The results demonstrated that the Japanese version of the AES scale shows adequate factorial reliability and validity, but different from the original version the "egocentrism personal fable" subscale which measures the feeling that oneself is special and unique was not extracted in the Japanese version. We found a moderate correlation between the non - social focuses of the AES scale and the public self-consciousness subscale of the self-consciousness scale. This correlation suggests that a strong attention of others' view on oneself results in the avoidance of others.
\end{abstract}

The Japanese version of the AES scale can examine egocentrism adequately together with sociocentrism and non - social focuses. As this scale is self-reporting and easy to complete, it may have practical utility in a clinical setting. J. Med. Invest. 55 : 254-259, August, 2008

Keywords : egocentrism, adolescent egocentrism-sociocentrism, Adolescent Egocentrism-Sociocentrism Scale, self-consciousness

Received for publication May 21, 2008 ; accepted July 3, 2008.

Address correspondence and reprint requests to Mayumi Yamamoto, the University of Tokushima Faculty of Integrated Arts and Sciences, 1-1, Minamijyosanjima-cho, Tokushima 7708502, Japan and Fax : +81-88-656-7192.

\section{INTRODUCTION}

In recent years, various adolescent psychiatric problems such as social withdrawal, eating disorders, and psychosomatic symptoms resulting from child abuse have been reported. In the backgrounds 
of them there are interpersonal problems that are related to a high degree of egocentrism (1-3). Egocentrism is characterized by focusing on self. It is a kind of perception of self as being unique and as being the object of others' thought.

The scale of Adolescent Egocentrism-Sociocentrism (AES) developed by Enright (4) has been often used to examine adolescent egocentrism in Western countries $(1,5)$. However, comparable studies that examine adolescent egocentrism in Japan have used subscores of the Yatabe-Guilford personality inventory (the YG test) (6). There are other studies which examined egocentrism by way of interviewing (6) and using the Szondi-test (7). However, these scales are indirect measurement and there is currently no appropriate scale for directly assessing adolescent egocentrism in Japan.

We tried to validate the AES scale for the examination of Japanese adolescent egocentrism. The AES scale measures egocentrism, sociocentrism, and non-social focuses. Egocentrism consists of three aspects : imaginary audience, personal fable, and self-focus. Imaginary audience refers to the tendency to think that others are paying far more attention to him or her than is actually the case. Personal fable refers to the perception that one is special and unique. Self-focus implies that the focus of one's thoughts is inward to toward the self rather than toward other people (8). The merits of the AES scale are based on the fact that it can measure egocentrism, sociocentrism, and non-social focuses aspects both directly and quantitatively.

Another important determining factor in adolescent interpersonal relationships is self-consciousness. Self-consciousness turns the attention towards oneself. According to Fenigstein (9), self-consciousness consists of public and private self-consciousness. Private self-consciousness refers to the degree of attention on internal aspects that are not directly observed by others, such as self-esteem, emotion, and mood. Public self-consciousness refers to the degree of attention on external aspects of the self that can be observed by others, such as one's clothes, hair style, words, and actions toward others. The self-consciousness scale is used to evaluate these two aspects (9).

The association of self-consciousness with social anxiety and eating disorders has been previously reported $(10,11)$. The Japanese version of the self-consciousness scale has been previously described (12) and subsequently used to evaluate relationships between social anxiety, eating disor- ders, and self-consciousness in Japanese subjects $(13,14)$. Elkind has stated that an adolescent who shows marked adolescent egocentrism also shows marked self-consciousness (8). However, Enright contends that the egocentrism and self-consciousness are distinct in theory, since, unlike adolescent egocentrism, self-consciousness is not concerned with cognitive distortions as a result of newly acquired abstract reasoning abilities (4). The correlation between egocentrism and self-consciousness was reported to be moderate $(r=0.23$ 0.46) in the study of Enright (4).

There are two purposes to our current study. First, we tried to develop the Japanese version of the AES scale and examined its factorial reliability and validity for use among Japanese students. Next, we investigated the relationship between the Japanese version of the AES scale and the Japanese version of the self-consciousness scale.

\section{METHODS}

\section{Participants}

We explained the purpose of the study in detail and asked 138 undergraduate students (74 males, 64 females) to fulfill the two scales. Among them, one student refused and 137 students agreed to participate and 104 students fulfilled the two scales completely. Consequently, the answers from these 104 students (61 males, 43 females) were evaluated. The age range of this final group was 18 to $24(\mathrm{M}=$ $18.7, \mathrm{SD}=0.8) .15$ subjects were students in the faculty of Integrated Arts and Sciences, 15 in the faculty of Medicine, 26 in the faculty of Pharmaceutical Sciences, and 48 in the faculty of Engineering.

\section{Procedure}

The participants were asked to complete the Japanese version of the AES scale and the Japanese version of the self-consciousness scale. They were told that their responses would be treated confidentially and anonymously. The entire procedure took about 50 minutes.

\section{Measurement}

The AES scale was translated into Japanese following the forward-backward method in which the initial translation was from English into Japanese. Subsequently, someone who was unaware of the original document translated the Japanese version 
back into English and the two English versions were analyzed for discrepancies. For the preparation of the Japanese version, it was necessary to update some of the terminology because Enright's script was completed 25 years ago. The back translation was validated by Prof. Enright.

For the Likert-type scale (15), the student read a statement and decided on the degree of importance using a 5 point scale. The scoring of each item ranges from 1 (no importance) to 5 (great importance). Examples of the items are "Thinking about my own feelings," "Buying anything I want," and "Trying to understand how the government works."

The Japanese version of the self-consciousness scale standardized by Sugahara (12) was also employed. This scale measures internal and external aspects of the self and 21 items were presented. Eleven items assess the public self-consciousness and 10 assess private self-consciousness. Each item has a 7 point scoring system using the Likert system (15). This score is rated on a scale from 1 (extremely uncharacteristic of me) to 7 (extremely characteristic of me).

\section{Statistical Analysis}

Statistical analysis was carried out with SPSS for Windows (Release 14.0 for Japanese edition). Exploratory factor analysis $(16,17)$ was performed on all samples. The internal consistency and reliability of each factor in the Japanese version of the AES scale was investigated with Cronbach's alpha reliability coefficient (17). A Cronbach's alpha $>0.7$ was taken as reliable. A factorial structure was examined using the principal factor method with varimax rotation. We also analyzed the unrotated solution and the sample adequacy, using the KaiserMeyer-Olkin (KMO) test (17). A Pearson correlation was used to examine the relationship between the Japanese version of the AES scale and the Japanese version the self-consciousness scale.

\section{RESULTS}

\section{Internal validity}

The following analysis incorporated both males and females as gender had no significant effect in the Japanese version of the AES scale. Exploratory factor analysis was performed for all 45 questions on the Japanese version of the AES questionnaire. The internal factor structure was examined using the principal factor method with varimax rotation. Four factors with eigenvalues of 7.69, 4.20, 2.89, and 1.90 were defined. The selective criterion for items was that the factor loading was greater than 0.30 in each case. Twelve items were deleted, because factor loading weight of these items did not reach 0.30 .

Thirty-three items remained at the end of the factor analysis. The cumulative proportion of variance explained was $43.97 \%$. The KMO value point was 0.75 . This showed that the factor analysis was appropriate. The internal consistency reliability coefficient (Cronbach's alpha) of the 33 items in the Japanese version of the AES scale was high (Cronbach's alpha $=0.84$ ).

The four factors in the Japanese version of the AES scale were further assessed (Table 1). For the first factor, sociocentrism, factor loading was great enough in 15 items. These items agreed with the sociocentrism item of the original version. In the second factor, non-social focuses, factor loading was great enough for 8 items. These items are included in non-social focuses items of the original version. For the third factor, egocentrism selffocus, factor loading was great enough in 5 items. These agreed with 5 egocentrism items (4 items in the self-focus and 1 item in the personal fable) of the original version of the AES scale. For the item 23, "Explaining my unique feelings and viewpoints to others so they can get some idea about what I am like", the factor loading was 0.331 for the third factor and 0.554 for the fourth factor. This item was included in the third factor as it helps to explain an individual's feelings towards others. In the original version, Enright also included this item in the self-focus even though the factor loading of this item was greater for personal fable than for the self-focus. In the fourth factor, egocentrism imaginary audience, factor loading was great enough in 5 items. These 5 items agreed with egocentrism items (3 items in the imaginary audience, 1 item in the personal fable, and 1 item in the self-focus) of the original version. The item 22 "Becoming real good at knowing what others are thinking of me", was contained in egocentrism self-focuses in the original version but contained in the fourth factor in the Japanese version. The item 33 was "Trying to get other people to know how it is like being me". The factor loading of item 33 was 0.311 for the third factor and 0.475 for the fourth factor. These items are related to imagining another person's thoughts. While the original version of AES scale 
consisted of three factors (sociocentrism, non-social focuses, and egocentrism) and egocentrism are subdivided into three subfactors (imaginary audience, personal fable, and self-focus), the Japanese version of the AES scale turned out to consist of

Table 1 Factor Analysis (Pattern Matrix) of the Japanese version of the AES scale

\begin{tabular}{|c|c|c|c|c|}
\hline \multirow[b]{3}{*}{$\begin{array}{c}\text { Item number } \\
\text { of AES }\end{array}$} & \multicolumn{4}{|c|}{ Factor loadings ${ }^{\star}$} \\
\hline & Factor 1 & Factor 2 & Factor 3 & Factor 4 \\
\hline & $\begin{array}{l}\text { Sociocen- } \\
\text { trism }\end{array}$ & Non-social & $\begin{array}{l}\text { egocentrism } \\
\text { Self-focus }\end{array}$ & $\begin{array}{c}\text { egocentrism } \\
\text { Imaginary } \\
\text { audience }\end{array}$ \\
\hline 26 & 0.844 & & & \\
\hline 18 & 0.813 & & & \\
\hline 17 & 0.750 & & & \\
\hline 30 & 0.735 & & & \\
\hline 42 & 0.721 & & & \\
\hline 35 & 0.719 & & & \\
\hline 27 & 0.711 & & & \\
\hline 37 & 0.673 & & & \\
\hline 24 & 0.651 & & & \\
\hline 39 & 0.598 & & & \\
\hline 5 & 0.587 & & & \\
\hline 2 & 0.566 & & & \\
\hline 34 & 0.555 & & & \\
\hline 6 & 0.526 & & & \\
\hline 13 & 0.337 & & & \\
\hline 38 & & 0.700 & & \\
\hline 25 & & 0.627 & & \\
\hline 29 & & 0.614 & & \\
\hline 31 & & 0.577 & & \\
\hline 3 & & 0.530 & & \\
\hline 10 & & 0.437 & & \\
\hline 20 & & 0.397 & & \\
\hline 4 & & 0.300 & & \\
\hline 28 & & & 0.791 & \\
\hline 40 & & & 0.694 & \\
\hline 12 & & & 0.641 & \\
\hline 1 & & & 0.603 & \\
\hline 23 & & & 0.331 & 0.554 \\
\hline 22 & & & & 0.673 \\
\hline 14 & & & & 0.617 \\
\hline 44 & & & & 0.557 \\
\hline 21 & & & & 0.536 \\
\hline 33 & & & 0.311 & 0.475 \\
\hline $\begin{array}{r}\text { Variance } \\
\text { explained }\end{array}$ & 6.86 & 2.81 & 2.52 & 2.33 \\
\hline $\begin{array}{r}\text { Cumulative } \\
\text { proportion of } \\
\text { variance } \\
\text { explained }\end{array}$ & 20.78 & 29.28 & 36.92 & 43.97 \\
\hline $\begin{array}{r}\text { Cronbach's } \\
\text { alpha }\end{array}$ & 0.92 & 0.78 & 0.76 & 0.74 \\
\hline $\mathrm{KMO}$ & 0.90 & 0.74 & 0.77 & 0.74 \\
\hline
\end{tabular}

*Loading of less than 0.30 were eliminated.

AES : Adolescent Egocentrism-Sociocentrism four factors (sociocentrism, non-social focuses, egocentrism imaginary audience and egocentrism selffocus).

\section{Reliability}

We investigated the internal consistency coefficient (Cronbach's alpha) of the Japanese version of the AES scale. Cronbach's alpha of each factor was greater than 0.70 , ranging from 0.92 (sociocentrism) to 0.74 (egocentrism imaginary audience). Also, the Cronbach's alpha reliability coefficient for the Japanese version of the self-consciousness scale was greater than 0.70 , with the public self-consciousness being at 0.84 , and the private selfconsciousness at 0.85 . The reliability coefficient of all factors was great enough.

The sociocentrism, non-social focuses, and egocentrism were found in the Japanese version of the AES scale comparable to the original version of the AES scale. The reliability of the Japanese version of the AES scale was thus confirmed. Egocentrism in the original version of the AES scale consists of three subfactors but only two in the Japanese version. The Japanese version of the AES scale did not have egocentrism personal fables subfactor, which is consciousness of oneself as a unique existence in the world.

Relationship between the AES scale scores and the self-consciousness scale scores

Correlations between the Japanese version of the AES scale (sociocentrism, non-social focuses, egocentrism self-focus, and egocentrism imaginary audience) and the Japanese version of the selfconsciousness scale (private/public) are shown in Table 2.

The correlation coefficient between the non-social focuses and public self-consciousness subscale was significant $(\mathrm{r}=0.316, \mathrm{p}<0.01)$. The correlation coefficient between the egocentrism imaginary audi-

Table 2 Correlation Coefficient between the Japanese version of the AES scale and the Japanese version of the Self-consciousness scale

\begin{tabular}{lcc}
\hline & \multicolumn{2}{c}{ the Self-consciousness scale } \\
\cline { 2 - 3 } & $\begin{array}{c}\text { Public } \\
\text { Self-Consciousness }\end{array}$ & $\begin{array}{c}\text { Private } \\
\text { Self-Consciousness }\end{array}$ \\
\hline the AES scale & & \\
Sociocentrism & -0.019 & 0.072 \\
Non-social focuses & $0.316^{\star *}$ & -0.082 \\
Self-focus & -0.054 & $0.473^{\star *}$ \\
Imaginary audience & $0.466^{\star *}$ & 0.181 \\
\hline
\end{tabular}

Pearson coefficient of correlation ${ }^{* *} \mathrm{p}<0.01$ 
ence and the public self-consciousness values was also found to be significant $(r=0.466, p<0.01)$. The correlation between the egocentrism self-focus and the private self-consciousness was significant $(r=0.473, p<0.01)$. No relationship between sociocentrism and self-consciousness was found.

\section{DISCUSSION}

In our present study, we translated the original version of the AES scale into Japanese and examined its factorial reliability and validity. We further examined whether egocentrism measured by the Japanese version of the AES scale was related to self-consciousness measured by the Japanese version of the self-consciousness scale in Japanese adolescents.

The factorial reliability and validity of the Japanese version of the AES scale was confirmed and this scale was standardized. The Japanese version of the AES scale consists of sociocentrism, nonsocial focuses, and egocentrism, in agreement with the original version. In the egocentrism scale, the imaginary audience and the self-focus aspects were found in the Japanese version of the AES scale as in the original version. However, different from the original version, the egocentrism personal fable subfactor was not found in the Japanese version. This subfactor is a measure of the feeling that oneself is special and unique. In Japan, although a person thinking of oneself as unique has been more positively regarded in recent years, conformity within a group is still considered of higher value in Japanese culture $(18,19)$. This may explain why the personal fable characteristic was not found in the Japanese version of the AES scale.

In terms of psychiatric problems and self-consciousness issues, it was reported that students with a high degree of public and private self-consciousness showed a higher tendency towards social phobia (13). Public self-consciousness, but not private self-consciousness, was found to be related to social anxiety $(10,11)$. Interestingly, patients with eating disorder were shown to have a high degree of public self-consciousness and a low degree of private self-consciousness $(14,20)$. When the public self-consciousness is too high, the difficulty in interpersonal relationship may emerge, and selfesteem may decrease. This can lead to various psychiatric problems.

The correlation between egocentrism measured using the Japanese version of the AES scale and the Japanese version of the self-consciousness scale appeared only moderate $(\mathrm{r}=0.466,0.473)$. This result supports the theory of Enright that egocentrism and self-consciousness are distinct from each other (4). However different from the result of Enright (4), we found a moderate $(r=0.316)$ correlation between non-social focuses and public self-consciousness. Non-social focuses indicates preference to personal life without communicating to others. This relationship supports an interpretation that a strong attention of others' view on oneself results in the avoidance of others. This could be considered a distinctive feature of Japanese people.

Egocentrism is an important aspect of the interpersonal relationship. Some clinical studies using the YG test have indirectly investigated the degree of egocentrism in patients with panic disorders, generalized anxiety disorders, and also eating disorders. The results of these assessments have shown that egocentrism levels become low when the symptoms improve (6). However, no scale has been previously employed in Japan to adequately examine egocentrism. Thus far, egocentrism has only been examined indirectly using an interview or the YG test. However, the Japanese version of the AES scale that we standardized in this study can examine egocentrism adequately as well as sociocentrism and non-social focuses. We therefore consider this scale to be a useful assessment tool with great potential for use in further studies.

As the participants were university students with a higher level of intelligence, it seems to be unclear whether or not they were representative of general adolescent. It is a limitation of this study.

\section{ACKNOWLEDGEMENT}

The authors are grateful to Professor R.D. Enright for permitting the Japanese version of the AES. To know the detailed contents of the AES scale, please contact Professor R.D. Enright at Department of Educational Psychology, University of Wisconsin-Madison.

\section{REFERENCES}

1. Jahnke HC, Blanchard-Fields F : A test of two models of adolescent egocentrism. J Youth Adolesc 32 : 313-326, 1993 
2. Vartanian LR : Adolescents' reactions to hypothetical peer group conversations : evidence for an imaginary audience? Adolescence 36 : 347 380, 2001

3. Burack JA, Flanagan T, Peled T, Sutton HM, Zygmuntowicz C, Manly JT : Social perspectivetaking skills in maltreated children and adolescents. Dev Psychol 42 : 207-217, 2006

4. Enright RD, Shukla DG, Lapsley DK : Adolescent Egocentrism-Sociocentrism and Self-Consciousness. J Youth Adolesc 9 : 101-116, 1980

5. Greening L, Stoppelbein L, Chandler CC, Elkin TD : Predictors of children's and adolescents' risk perception. J Pediatr Psychol 30 : 425435, 2005

6. Nukina S, Wang H, Kamei K, Kawahara, R : Intensive Naikan therapy for generalized anxiety disorder and panic disorder : clinical outcomes and background. Psychiatria neurologia Jpn 107 : 641-666, 2005 (in Japanese)

7. Matsubara Y, Nishimura C:A study on the personality factor of the vocational indecision by Szondi-test: In relation to the identity. Kawamura Gakuen Woman's University 18 : 141-162, 2007 (in Japanese)

8. Elkind D : Egocentrism in Adolescence. Child Dev 38 : 1025-1034, 1967

9. Feningstein A, Scheier MF, Buss AH : Public and private self-consciousness : Assessment and theory. J Cons Clin Psychol $43: 522-527$, 1975

10. Hope DA, Heimberg RG : Public and private self-consciousness and social phobia. J Pers Assess 52:626-639, 1988

11. Saboonchi F, Lundh LG, Öst LG : Perfection- ism and self-consciousness in social phobia and panic disorder with agoraphobia. Behav Res Ther 37 : 799-808, 1999

12. Sugahara $\mathrm{K}:$ An attempting to construct the self-consciousness scale for Japanese. Jpn J Psychol 55 : 184-188, 1984 (in Japanese)

13. Nabeta $\mathrm{Y}$ : The anthropophobia, dysmorphophobia and eating disorder from a standpoint of self-consciousness. In : Social phobia and dysmorphophobia. Kongo Shuppann, Tokyo 1997, pp.185-208 (in Japanese)

14. Hirohashi A : Tendency for eating disorder and public self-consciousness. Clin Dev Psychol 4 : 32-40, 2005 (in Japanese)

15. Wakita $\mathrm{T}$ : Assessment of the distance between categories in rating scales by using item response model. Jpn J Psychol 75 :331-338, 2004 (in Japanese)

16. Knafl GJ, Grey M : Factor Analysis model evaluation through likelihood cross-validation. Stat Methods Med Res 16:77-102, 2007

17. Matsuo T, Nakamura T: Factor Analysis, Kitaoujishobou, Kyoto, 2002 (in Japanese)

18. Nakamura $\mathrm{H}$ : Ways of thinking of eastern peoples : India-China-Tibet-Japan, An East- West Center Book The University Press of Hawaii, Honolulu, 1964, pp.407-530

19. Doi $\mathrm{T}$ : The anatomy of self : the individual versus society, Kodansha International Tokyo and New York, 1988

20. Forbush K, Watson D : Emotional inhibition and personality traits : a comparison of women with anorexia, bulimia, and normal controls. Annu Clin Psychiatry 18 : 115-121, 2006 